\title{
IUCN
}

\section{IUCN Niger Delta Panel: Stories of influence}

Gillian S. Martin Mehers
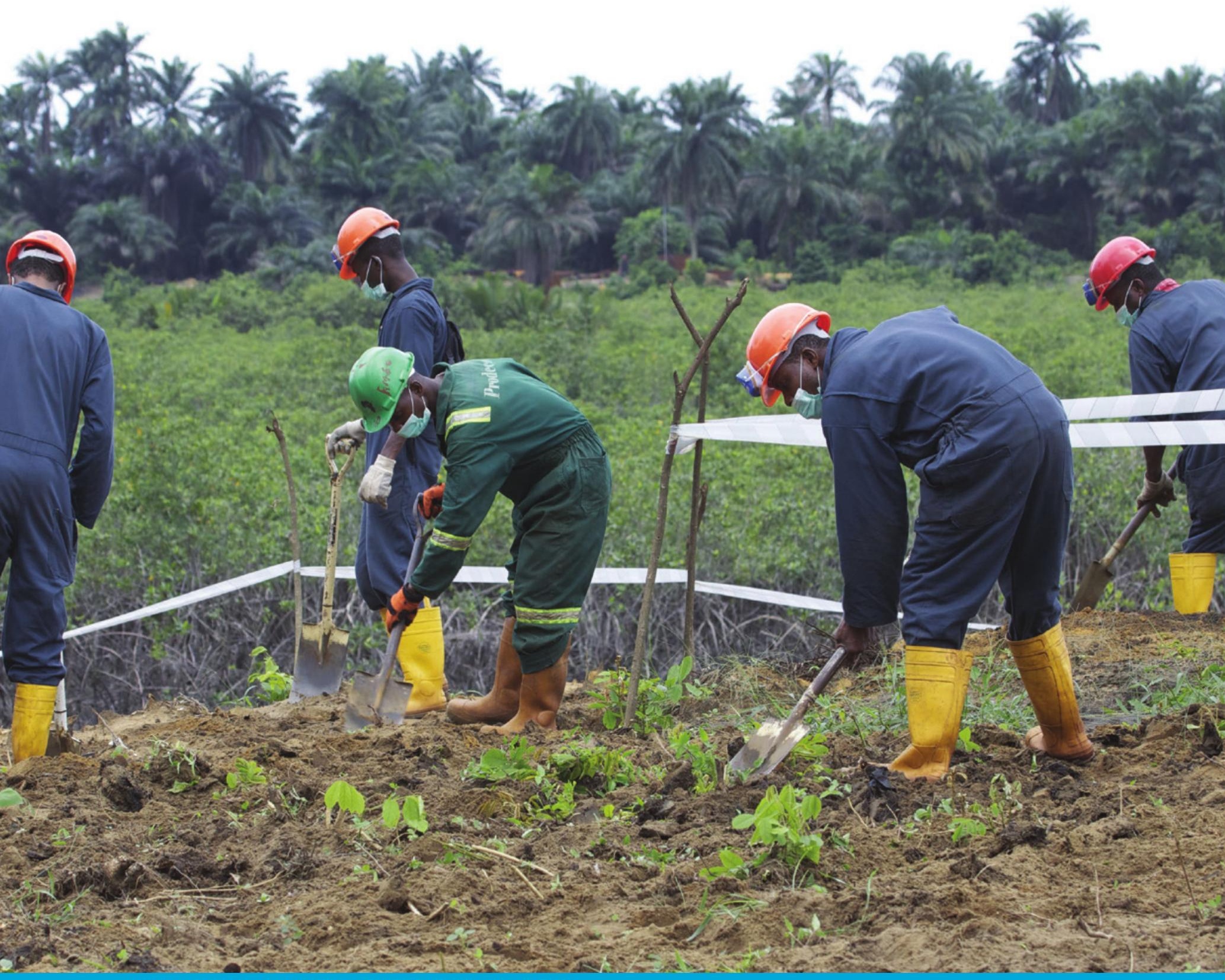

INTERNATIONAL UNION FOR CONSERVATION OF NATURE 


\section{ABOUT IUCN}

IUCN is a membership Union uniquely composed of both government and civil society organisations. It provides public, private and non-governmental organisations with the knowledge and tools that enable human progress, economic development and nature conservation to take place together.

Created in 1948, IUCN is now the world's largest and most diverse environmental network, harnessing the knowledge, resources and reach of more than 1,300 Member organisations and some 13,000 experts. It is a leading provider of conservation data, assessments and analysis. Its broad membership enables IUCN to fill the role of incubator and trusted repository of best practices, tools and international standards.

IUCN provides a neutral space in which diverse stakeholders including governments, NGOs, scientists, businesses, local communities, indigenous peoples organisations and others can work together to forge and implement solutions to environmental challenges and achieve sustainable development.

Working with many partners and supporters, IUCN implements a large and diverse portfolio of conservation projects worldwide. Combining the latest science with the traditional knowledge of local communities, these projects work to reverse habitat loss, restore ecosystems and improve people's well-being.

www.iucn.org

https://twitter.com/IUCN/ 
IUCN Niger Delta Panel: Stories of influence

Gillian S. Martin Mehers 
The designation of geographical entities in this book, and the presentation of the material, do not imply the expression of any opinion whatsoever on the part of IUCN concerning the legal status of any country, territory, or area, or of its authorities, or concerning the delimitation of its frontiers or boundaries.

The views expressed in this publication do not necessarily reflect those of IUCN.

Published by: $\quad$ IUCN, Gland, Switzerland

Copyright: $\quad$ @ 2018 IUCN, International Union for Conservation of Nature and Natural Resources

Reproduction of this publication for educational or other non-commercial purposes is authorised without prior written permission from the copyright holder provided the source is fully acknowledged.

Reproduction of this publication for resale or other commercial purposes is prohibited without prior written permission of the copyright holder.

Citation: Martin Mehers, G.S. (2018). IUCN Niger Delta Panel: Stories of influence. Gland, Switzerland: IUCN.

DOI: $\quad$ https://doi.org/10.2305/IUCN.CH.2018.23.en

Cover photo: $\quad$ Remediation work at Lewe spill site, Rivers State. Courtesy of SPDC.

Editing by: $\quad$ Deborah Murith

Layout by: $\quad$ Diwata Hunziker

Printed by: $\quad$ BSR Imprimeurs

Available from: $\quad$ IUCN (International Union for Conservation of Nature)

Global Business and Biodiversity Programme

Rue Mauverney 28

1196 Gland

Switzerland

Tel +41229990000

Fax +41229990002

www.iucn.org/resources/publications

The text of this book is printed on paper made from wood fibre from well-managed forests certified in accordance with the rules of the Forest Stewardship Council (FSC). 


\section{Contents}

Acknowledgements iv

Preface v v

Executive summary vii

1 IUCN Niger Delta Panel and the Niger Delta conservation 1

challenge 5

2 Influencing company policy and practice 11

3 Influence and impacts in IUCN 14

4 Working with regulators $\quad 15$

5 Influence in the community and on other initiatives 17

$\begin{array}{ll}\text { Next steps and conclusion } & 18\end{array}$

Annex: List of interviews 


\section{Acknowledgements}

We would like to thank all those who contributed their reflections and observations on the work of the Niger Delta Panel, including the Panel Chair Dr Uzoamaka Egbuche, and Panel members Dr Muhtari Aminu-Kano, Dr James Kairo, Professor Dan Laffoley, Professor Olaf Linden. We would also like to acknowledge the important contribution of the first Chair, the late Dr Emmanuel Obot, who positively influenced the Panel's early process, the late Professor Alex Chindah, Professor Ikem Ekewozor and Dr Victor Obinna. IUCN's Members and expert Commissions were instrumental in the Panel's creation and management and warm thanks are deserved by the Nigerian Environmental Study Action Team, Nigerian Conservation Foundation and CERASE Environmental Services Limited, and IUCN's Commission on Environmental, Economic and Social Policy (CEESP).

From SPDC and Shell, support and insights came from Kim Bye Bruun, Chinyere Ozumba and Pankyes Hirse, as well as Deric Quaile, formerly of Shell Global Solutions. IUCN's reflections came from Stewart Maginnis, Steve Edwards, Rachel Asante-Owusu and Gerard Bos, with support from Leigh Ann Hurt. We would also like to thank the author, Gillian Martin Mehers, who conducted the interviews, drafted and revised the text throughout the consultation process. This report is the result of a positive and collaborative effort.

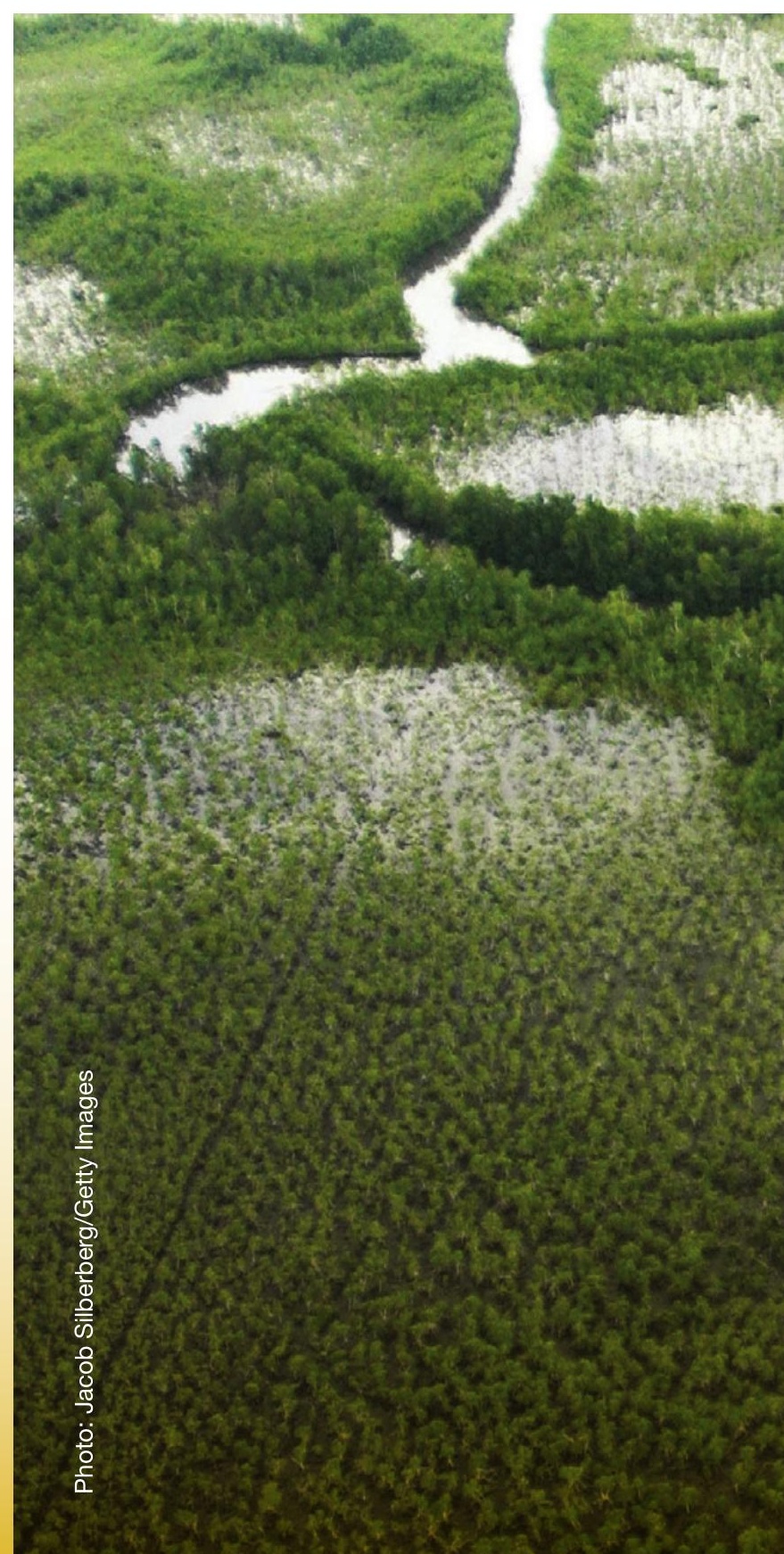




\section{Preface}

This report is the second in a series that describes IUCN's work with independent scientific and technical advisory panels. By sharing these Stories of influence, we hope not only to demonstrate the influence that the Niger Delta Panel has had on the remediation of oil spills and biodiversity management in the Niger Delta, but also to illustrate how these intiatives can serve as examples for addressing conservation and development challenges elsewhere in the world - highlighting that collaboration is central to finding long-lasting solutions to today's pressing challenges.

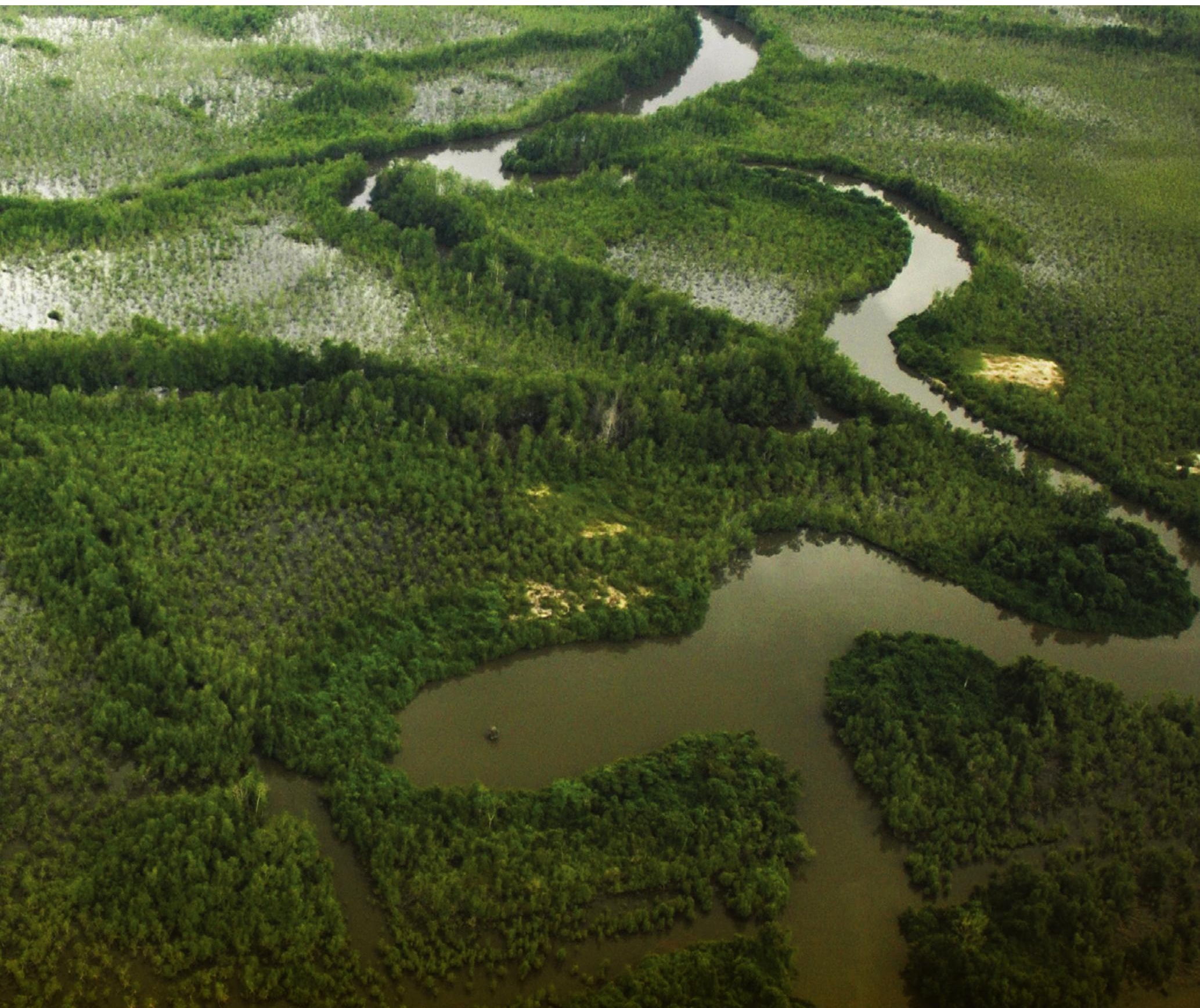


$3-5,4=2$

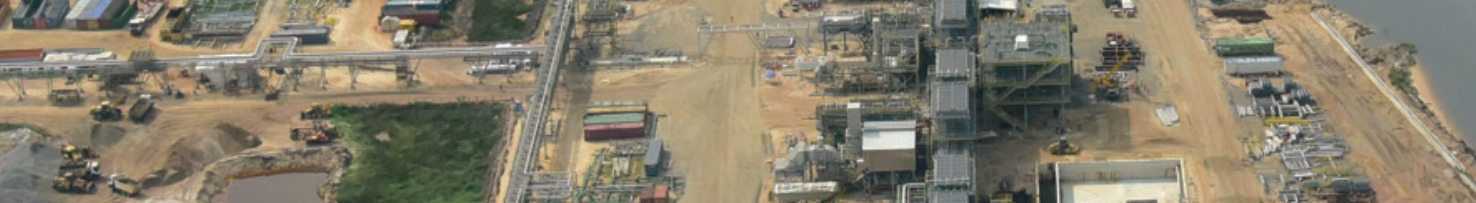

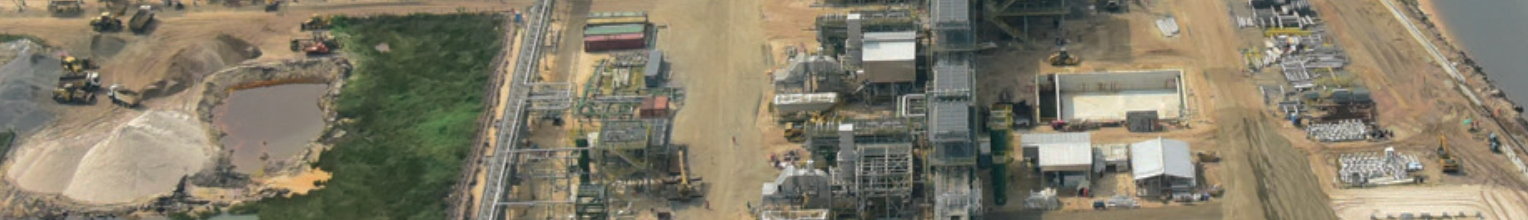

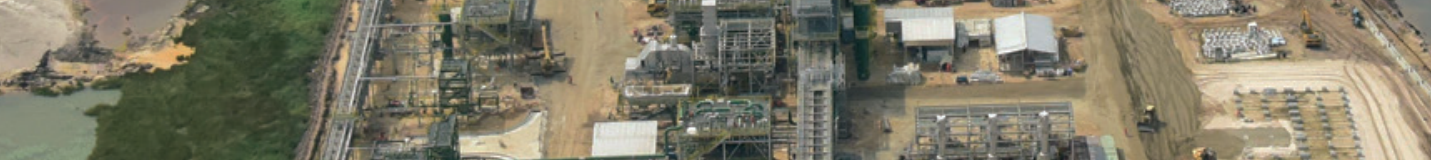

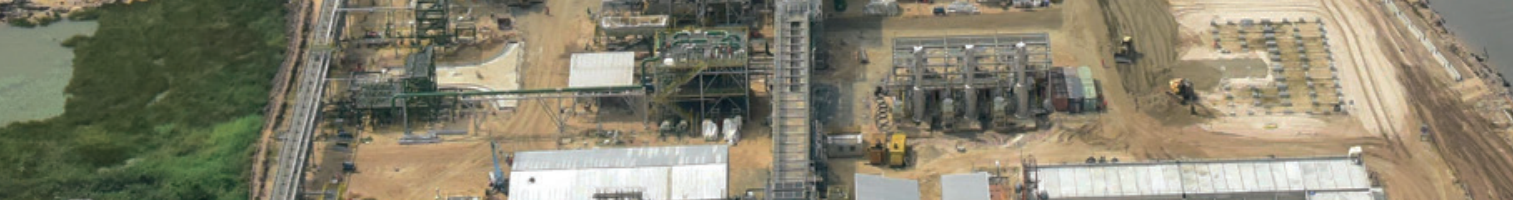

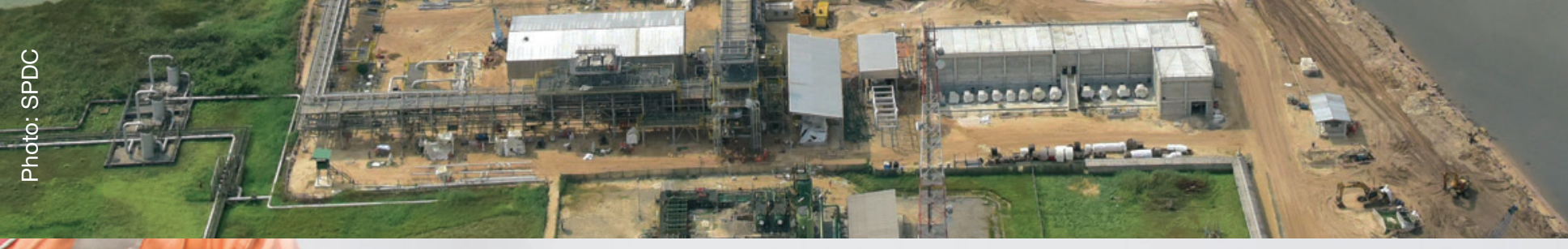
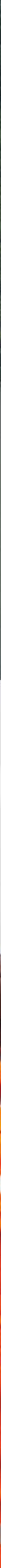


\section{Executive summary}

During the period 2012-2016, a group of international and national scientists convened and facilitated by IUCN, worked together to produce a set of focused recommendations on the remediation and rehabilitation of biodiversity habitats in the Niger Delta. With a range of technical expertise from oil spill recovery to mangrove rehabilitation, the IUCN Niger Delta Panel (IUCN NDP) was established at the request of Shell Petroleum Development Company of Nigeria Limited (SPDC) in its capacity as operator of the SPDC Joint Venture.

Working independently from SPDC but in close cooperation with the company, the Panel presented its advice in two major reports to SPDC, and collaborated in a number of other publications and guidance documents. The IUCN Niger Delta Panel: Stories of influence captures the effects of the Panel's work and explores the influence that ensued directly from their recommendations and from the collaborative process they followed to produce them.

Derived from evidence and observations from the actors most deeply involved - the Panel members, SPDC staff and IUCN - influence can be found in both expected and surprising areas. SPDC's policy and practice has changed because of the NDP's work; it helped the company strengthen its internal capacity in remediation and biodiversity conservation and it fostered improvements in SPDC's oil spill and emergency response approach. The Panel's recommendations provided SPDC with a pathway for improvement in remediation execution and as a result a remediation standard was developed. Mangrove habitat guidance, used both internally and shared internationally, was an output catalysed by the IUCN NDP. The Panel helped the company develop a biodiversity conservation strategy, and provided input and support for SPDC's move towards implementation of a risk-based approach to oil spill remediation in the Niger
Delta. This latter area of work launched a process involving regulators from the Nigerian Department of Petroleum Resources that included: formation of a working group to develop a set of recommended risk-based screening levels for soil and groundwater in the Niger Delta; a capacity development programme for regulators and; a collaborative pilot test of the risk-based approach.

The Panel's work and process also inspired changes within IUCN. It helped strengthen its capacity and confidence to work in highly complex environments, increasing the organisation's risk tolerance and risk capacity. The experience helped IUCN formalise its peer review process, increasing the robustness and quality of its publications. As an early example of an Independent Scientific and Technical Advisory Panel (ISTAP), the Panel provided a proof of concept for the organisation, and learning from this experience has fed directly into the creation by IUCN of subsequent ISTAPS in other parts of the world.

The Panel proved to be a rich learning experience for all parties involved and, after five years of active operation, its influence is still being felt. The Panel's formal recommendations are now being followed up in a next stage of collaboration between IUCN and SPDC, as well as a number of other partners, who have formed the Niger Delta Biodiversity Technical Advisory Group (BTAG) that will continue to monitor the Panel's recommendations and the sites that have been remediated from the biodiversity perspective. 


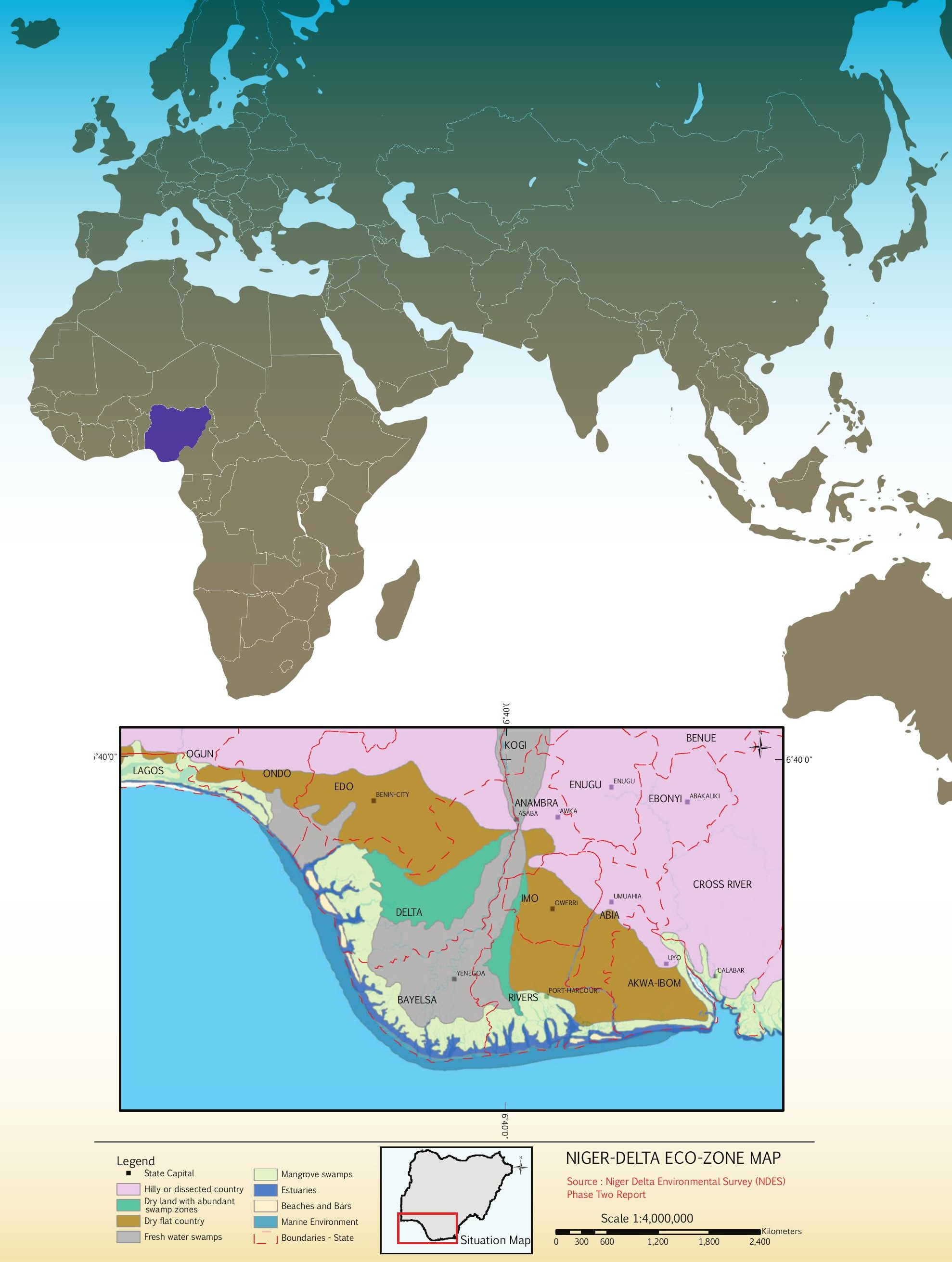




\section{IUCN Niger Delta Panel and the Niger Delta conservation challenge}

\section{WORKING WITH THE COMPLEXITY OF A PRODUCTIVE AND FRAGILE ENVIRONMENT}

The Niger Delta has featured in the media for decades, bringing to global attention the challenges of environmental impact as a result of oil spills in this resource rich, yet economically under-developed part of Nigeria.

With its immense reserves of oil and gas, there have been hundreds of reports of deliberate sabotage and organised oil theft from pipelines, criminality, and related consequences of oil spills impacting the fragile Niger Delta biodiversity.

The Niger Delta is an extensive and unique ecosystem. The rain and flood forests, swamps and unique mangrove ecozones are home to a large number of species and contain biodiversity not found anywhere else in the world. The environment is also an important source of livelihood for a significant sector of the Niger Delta population through farmlands and fishing grounds.

\section{FOCUSING THE WORK OF THE IUCN NIGER DELTA PANEL}

In 2012, Shell Petroleum Development Company of Nigeria Limited (SPDC) request IUCN for scientific advice on the remediation and rehabilitation of biodiversity habitats in the Niger Delta. In response, IUCN established an independent expert advisory group referred to as the IUCN Niger Delta Panel (IUCN NDP). The Panel was established to operate in a manner that was independent from SPDC, the IUCN Secretariat and other third-party influences. The Panel's work was endorsed by IUCN Members in Nigeria, including Nigerian Environmental Study/Action Team (NEST), Nigerian Conservation Foundation and CERASE
Environmental Services Limited. In particular, the Panel benefited from the leadership of a prominent member of IUCN's expert Commission on Environmental, Economic and Social Policy (CEESP), Professor Emmanuel Obot, who sadly passed away in the first year of the NDP's work.

The efforts of the IUCN NDP focused on delivery of independent science-based recommendations globally with the aim to help SPDC improve its remediation work and support biodiversity recovery in oil spill-affected areas.

At its inception, both IUCN and SPDC considered the Panel's work within the greater context of the Delta as paramount. The Panel needed to understand and take into consideration the dynamics and challenging historic and contemporary context in the region, while offering concrete and practical recommendations to specific non-technical challenges faced by SPDC in their onshore operations.

Ultimately, the Panel's work and subsequent recommendations would cover five broad areas:

- Redefining environmental management procedures;

- Revising oil spill response procedures;

- Working on new, but proven, scientific approaches to boost and support in situ biological remediation and rehabilitation processes;

- Supporting the sustainability of remediation at the community level; and

- Developing a biodiversity strategy for the Niger Delta. 


\section{WHO'S WHO?}

\section{IUCN Niger Delta Panel (IUCN NDP)}

consisted of a Chair and six other international and national scientists and experts from universities and private research institutions. The Panel, which was convened and administered by IUCN, operated during the period 2012-2016.

\section{IUCN}

managed and facilitated the IUCN Niger Delta Panel. IUCN also helped maintain the independence of the Panel and ensured the transparency of the Panel's reports and recommendations.

\section{Nigerian Environmental Study Action Team (NEST)}

is a national non-governmental organisation which is an IUCN Member in Nigeria. NEST was involved in the creation of the NDP; it endorsed and supported the initiative through providing in-country logistical and administrative support.

\section{Shell Petroleum Development Company of Nigeria Limited (SPDC)} is the operator of a joint venture (SPDC JV) between the government-owned Nigerian National Petroleum Corporation (55\% share), SPDC (30\%), Total E\&P Nigeria Ltd (10\%) and the ENI subsidiary Agip Oil Company Limited (5\%). It is focused on onshore and shallow water oil and gas production in the Niger Delta and operates around 1,400 oil and gas wells, a network of approximately 4,000 km of oil and gas pipelines and flowlines, nine gas plants and two major oil export terminals. It also operates one power plant.

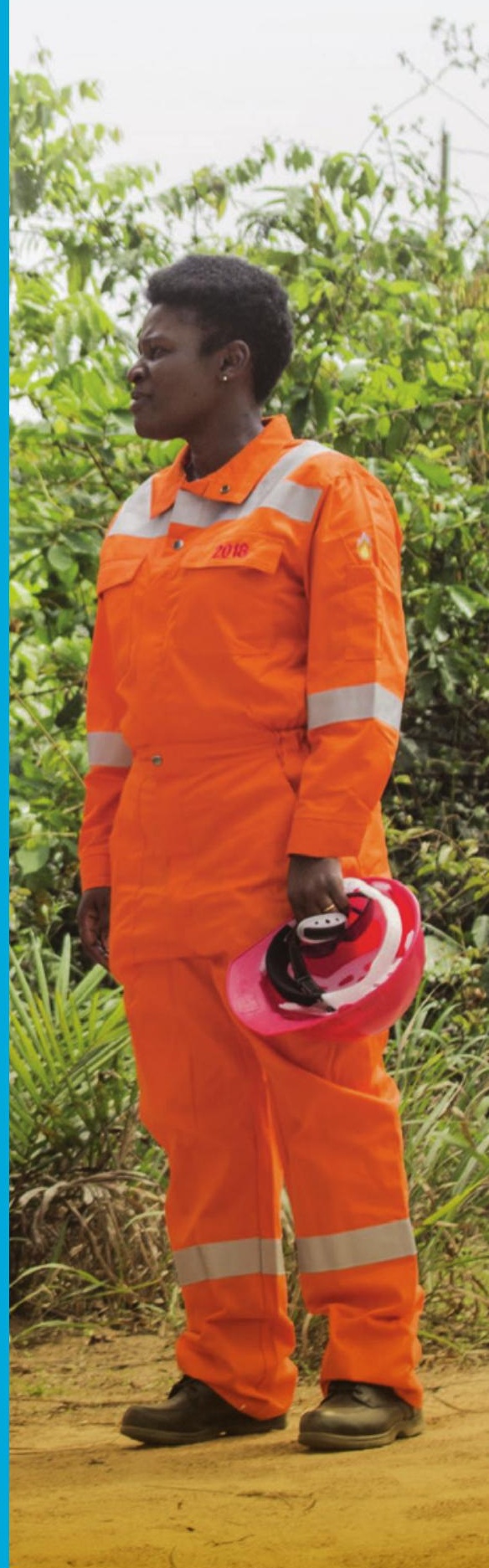




\section{HOW THE IUCN NIGER DELTA PANEL OPERATED}

Prior to the formal start of the IUCN Niger Delta Panel's work, its members were identified and engaged by IUCN in their individual capacities as scientists. During its five years of operation, 2012-2016, the Panel followed a process that included consultation and information collection with a range of stakeholders; discussions among themselves and with SPDC through a schedule of face-to-face and virtual meetings; and the production of written recommendations specifically for SPDC.

The Panel began with a number of in-person meetings to develop its baseline understanding of the situation and build relationships amongst the Panel members and with counterparts in SPDC and IUCN. The Panel meetings were structured to provide a forum for learning about the SPDC context and challenges, to facilitate discussion among Panel members and SPDC experts, and to generate and explore ideas and options for SPDC.

Early on in the process, in addition to its face-to-face and virtual meetings, the Panel conducted several field studies in different parts of the Delta. The aim of these visits was to collect soil samples and carry out visual inspection of oil spill impacts and existing biodiversity recovery efforts. Eventually, security and logistical issues curtailed further field work by the Panel itself. SPDC followed up with a set of Panel-recommended experiments in a controlled area within Obigbo community near Port Harcourt. The test included seven amendments assessed for their ability to improve landfarming of hydrocarbons in soils. The peer-reviewed study was published in the journal Science of the Total Environment (2017) (see box).

The emergence of the Ebola crisis in West Africa, which hit in 2014 and continued into early 2016, along with security issues around the 2015 elections, effectively halted travel in the region at the height of the Panel's work. A virtual meeting format therefore became the modus operandi. During this period, five renowned biodiversity experts based in Nigeria carried out an assignment for the Panel. The group consisted of foremost Nigerian academics knowledgeable on different taxonomic groups. They produced two synthesis reports on the status and trends of biodiversity in the Niger Delta, which served as input to the Panel's recommendations on biodiversity.

As an independent scientific panel, maintaining some distance from SPDC was of critical importance to the Panel's work. Independence was assured by IUCN, as the Panel convener, and by the individual Panel members through their Terms of Reference, the assumption being that they were open and free to identify issues and make recommendations for SPDC's consideration. During its work, however, Panel members did maintain regular and continuous contact with relevant SPDC staff, who joined the formal meetings, and were asked for information, explanations and feedback throughout the process. The Panel's independence was considered to improve the quality of its results, as well as the legitimacy of its work in the eyes of all stakeholders, including the science community. 


\section{THE PANEL'S KEY WRITTEN OUTPUTS}

The Panel produced two major reports during its work. In 2013 it produced its first main report of recommendations, Sustainable remediation and rehabilitation of biodiversity and habitats of oil spill sites in the Niger Delta, which was followed up with the identification of areas of further collaboration between SPDC and the IUCN NDP. The second report, Developing a biodiversity conservation strategy for the Niger Delta, written at the end of the Panel's formal work, was published in 2018, and provided SPDC with more focused advice on strengthening the biodiversity aspects of its oil spill remediation work. These reports are publicly available and can be found archived on IUCN's online portal.

How the IUCN NDP process and its recommendations influenced the company is elaborated further in the next section.

Sustainable remediation and rehabilitation of biodiversity and habitats of oil spill sites in the Niger Delta: Main report including recommendations for the future A report by the independent IUCN Niger Delta Panel (IUCN NDP) to the Shell Petroleum Development Company Ltd of Nigeria (SPDC). Gland, Switzerland: IUCN, July 2013.

Developing a biodiversity conservation strategy for the Niger Delta: Integrating biodiversity considerations into SPDC's operations

The second report by the IUCN Niger Delta Panel, 2018. Gland, Switzerland: IUCN, 2018.

Comparison of landfarming amendments to improve bioremediation of petroleum hydrocarbons in Niger Delta soils Published in Science of The Total Environment: Vol. 596-597, 15 October 2017, pp. 284-292. 


\section{Influencing company policy and practice}

\section{INFLUENCE AND IMPACTS IN THE COMPANY}

There were a number of motivations for SPDC's initial request for an independent scientific panel, among these were the desire for greater transparency, and the realisation that the company could benefit from independent expert support to improve its oil spill remediation and biodiversity recovery work. The Shell Group was already working with IUCN on another independent scientific technical advisory panel - the Western Gray Whale Advisory Panel (WGWAP) - and felt that a similarly structured collaboration with an independent panel of experts could help improve SPDC's Niger Delta remediation and rehabilitation work.

Although Shell had experience from working with IUCN in this way through the WGWAP panel, SPDC itself was new to this type of collaboration. Participating in a process that involved a group of independent scientists reviewing, analysing and presenting recommendations to strengthen its practice in oil spill remediation and habitat recovery was a new experience for SPDC. Although SPDC was, in principle, open to the idea of seeking independent assurance and verification of its activities in this area, they experienced the process as challenging at times. Over time, the relationship evolved. Towards the end of the Panel's formal work with SPDC, their collaboration developed into an authentic peer exchange and alignment around effective implementation of Panel recommendations to facilitate long-term biodiversity recovery and ecosystem protection.

Not only did the Panel make recommendations that drove SPDC towards improved remediation and biodiversity conservation, it also provided a new format for doing so. The Panel meetings created a platform for dialogue and a forum for the external Panel members, Shell Group experts and SPDC operational teams to discuss solutions to issues faced in the Delta. Involved in this was the explicit challenge of changing current practice. Thus, the process provided an opportunity for collective learning, trust building, and a nuanced development of an appreciation by the Panel for the context within which SPDC operated in the Niger Delta. SPDC developed a similar appreciation for the input and independence of the Panel's work.

\section{STRENGTHENING INTERNAL CAPACITY}

One of the first changes SPDC made as a result of its engagement with the Panel process was to strengthen its remediation and biodiversity recovery teams. A Project Manager was appointed to oversee and manage the remediation improvement programme. Based in Port Harcourt, the Project Manager worked with the Panel throughout the process. This provided a "home" within the company for the Panel's work, effectively increasing the touch points among the Panel members, IUCN and SPDC, and helped ensure ongoing focus by the company on the Panel's work.

The relationship-building process over the course of the collaboration helped the Panel endure some challenging situations, such as the traumatic loss of the first IUCN NDP Chair in an airplane accident. In addition, there were staff changes in IUCN, and the move from a face-to-face meeting format to more virtual work. Having continuity within SPDC, through a dedicated Project Manager, helped maintain stability and continuity, as well as ground the IUCN NDP's work within the company.

The Panel's recommendations and focus on strengthening company practice resulted in an overall upskilling of SPDC operational teams and ongoing assurance of remediation activities based on an updated remediation management plan and internal guidance 
documents. This was undertaken by a newly established SPDC assurance team, ensuring continuous improvement and implementation of international best practice.

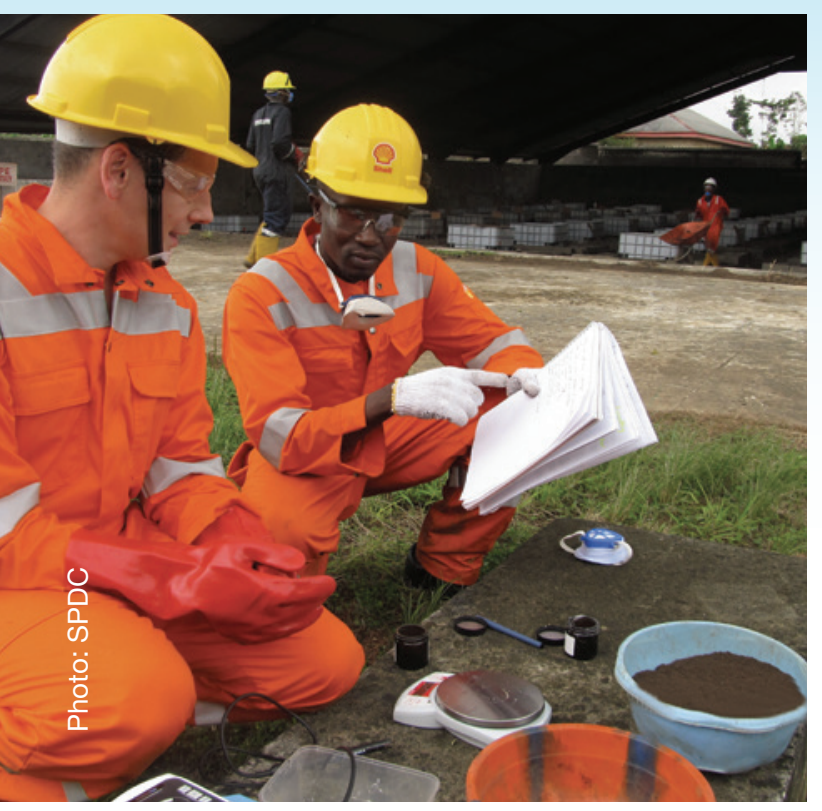

\section{IMPROVING SPDC COMPANY PRACTICE IN A RANGE OF TECHNICAL AREAS}

The Panel recommendations also led to a number of practical changes in company practice and approach, particularly in oil spill and emergency response, remediation and management procedures. Each of these changes were influenced directly by the work of the Panel as described below.

\section{- Improving the oil spill and emergency response approach}

On oil spill response, Panel recommendations focused on improvements in the speed of delivery and nature of intervention. When a leak is identified within SPDC areas of operation, the impacted infrastructure is immediately shut (production stopped) and efforts made to contain any spilled oil. A joint investigation visit is then carried out to establish the cause and volume of oil spilled with representatives from communities, regulators, government security agencies, state government and the company; sometimes local NGOs are invited as observers. This is a regulated procedure done within 24 hours of the spill, provided it is safe to do so and the community has provided access. Once the investigation has concluded and the cause of the spill has been determined, a team is mobilised to clean up the spill site irrespective of cause. In the case of operational spills, compensation is paid to people and communities impacted by the spill. A remediation action plan is then prepared, and the remediation of contaminated soil subsequently takes place.

The Panel's recommendations changed how this process is set up and the speed of intervention. The regulators - Nigerian National Oil Spill Detection and Response Agency (NOSDRA) and the Department of Petroleum Resources (DPR) - are involved throughout and issue site remediation certifications once the contaminant levels have reached regulatory limits.

The Panel identified in their recommendations the need to understand site-specific conditions for effective remediation. This articulated need resulted in SPDC developing a new set of Conceptual Site Models (CSMs) for the identified Niger Delta ecozones: lowland forest, flood forest, swamp forest, mangrove swamps and coastal barrier islands. These models support differentiated evaluation of risks if oil spills occur within any of the ecozones, as each has unique characteristics and site-specific conditions. The models continue to provide a framework for risk evaluation and help the selection of the most appropriate mitigation, remediation and rehabilitation options.

\section{- Developing a new remediation standard}

The IUCN NDP recommendations provided the SPDC team with a pathway for improvement 
in remediation execution. Based on Panel recommendations, SPDC developed a remediation standard, which outlines SPDC's requirements for the remediation teams. The standard is based on experience within the company and recommendations from the Panel and involved an iterative dialogue with the Panel members. The standard sets out expectations in terms of outcome, and outlines standards to which the company internally commits. This now guides the remediation approach taken by SPDC.

Scientific trials were carried out by SPDC, effectively testing the Panel's recommended remediation techniques. These large-scale landfarming experiments, using an extensive range of treatments, were conducted to study the degradation of oil in contaminated soils.

Landfarming is a well-practiced technique used in the Niger Delta, and elsewhere, to bioremediate crude oil contamination in soils with the objective of restoring the land to conditions acceptable to human health and the environment. It stimulates the natural microbial processes that break down and use the carbon-rich oil contamination as a source of food and energy, ultimately leading to its removal. The key to the process is providing the microbes with the nutrients they need to perform optimally. Landfarming is a tried and tested approach to reduce the concentration of oil in soils. To improve the effectiveness of this process, the IUCN NDP proposed the use of amendments, such as biosurfactants, enzymes and sorbents.

The trials were conducted in the first half of 2016, followed by result analyses. International remediation experts and scientists were involved in the study, in addition to members of the Panel. It was found that the treatments were successful in removing up to $53 \%$ of the total petroleum hydrocarbon in the soil within 16 weeks. A comparison between different treatments demonstrated that most were no more effective than adding agricultural fertilizer alone.

As a part of the follow-up on the Panel's recommendations, SPDC is collaborating with IUCN and the Nigerian Conservation Foundation to monitor the long-term biodiversity recovery of remediated sites.

Remediation work also has a social performance component. SPDC has a tradition for actively involving communities in the company's work. The IUCN NDP advised even more openness and more community involvement, including the integration of impact assessment, biodiversity, remediation and response to oil spill work in SPDC's Global Memorandum of Understanding with community clusters. SPDC already involves community contractors in their remediation work and is open about the fact that this must be done in a manner that does not incentivise sabotage against its pipeline infrastructure. Local communities are involved in clean up and remediation of operational spills; however, when oil spills are confirmed to be the result of theft or sabotage, the recovery and remediation work is managed by local contractors from other parts of the Niger Delta.

\section{- Elaborating on mangrove habitat guidance}

With over $3,100 \mathrm{~km}$ of coastline and an estimated 1 million hectares covered in mangrove forests, the Niger Delta is the location of the largest mangrove system in Africa, and one of the largest in the world. The Panel noted that each ecosystem in the Niger Delta demanded a different approach following oil spills, prompting the development of the CSMs described previously. Mangrove ecosystems are particularly valuable ecosystems from a number of perspectives. From the climate perspective, they are important as carbon sinks; they provide 
nurseries for coastal fisheries, timber and forest products, and guard against erosion and storm surges. For all of these reasons, this makes them valuable from the livelihood and ecosystem services perspective as well.

Successful rehabilitation of impacted mangroves is challenging due to the significant amount of time they need to regenerate, and it requires site-specific considerations. Although oil spills in these areas are not frequent, SPDC has had a keen interest in improving its management procedures and consulted the Panel on how to best handle them when they occur. Thus, the Panel, which included a mangrove specialist, identified rehabilitation in this important ecozone as an area of great importance and provided a set of recommendations for scientifically viable ways to strengthen the company's practice in this habitat. The resulting mangrove restoration plan advocated active planting and monitoring of mangroves in oil-affected areas. SPDC took the recommendations to the next level.

With the collaboration of two other external experts hired by SPDC, two web-based information sessions were hosted by the company, attracting a wide audience including regulators, NGOs and other international and local experts. Those participating were invited to have a discussion and share their experience on the best approach to handle oil spills affecting mangrove ecosystems. Built on information included in the 2013 IUCN NDP Report, this process resulted in a guidance document titled, "Management and Adaptive Monitoring of Mangrove Habitats in the Niger Delta", produced by SPDC in 2016.

This best practice guidance was developed by SPDC together with IUCN and other external international specialists for use by SPDC and others working on oil spills in mangrove forests. It includes a methodology for planning, implementation and adaptive monitoring of mangroves when rehabilitation efforts are needed. Available from SPDC, the aspiration is that this is a living document and that those who use the guidelines anywhere in the world can share case studies and lessons learned from these application experiences. SPDC commits to sharing its own learning by updating the document as it implements the guidelines in the Niger Delta.

This unique document establishing new best practices has continued to garner attention nationally in Nigeria, within Shell and in the broader international soil and groundwater community. Regulators expressed an interest in this document, including those from the DPR and NOSDRA. As Shell companies work to protect mangroves in other locations, such as the Gulf of Mexico, having best practices established is of great value. The findings were also presented at the 2017 AquaConSoil annual conference in France, together with the work done to establish Risk-Based Screening Levels (RBSL) in Nigeria and the work undertaken to map the Niger Delta ecozones. As noted, these were inspired by, and expanded, following input from the Panel.

\section{- Implementing a risk-based approach}

The IUCN NDP has provided input and support to SPDC as it has moved towards implementation of a risk-based approach to remediation in the Niger Delta. The use of a risk-based approach has been considered international best practice for more than a decade, and Shell has worked with regulators around the world to adapt the approach to the local contexts in which they operate. Through the work of the Panel, SPDC was encouraged to adopt this in Nigeria also.

SPDC and the Panel had a series of discussions and meetings focusing on regulatory standards, to explore if they were suitable and appropriate. Their comparison of standards from other parts of the world challenged the current practice and 
regulatory standards to which SPDC complied. The work concluded with a recommendation to advocate, demonstrate and build capacity among regulators for a new way of working, where locally adopted RBSLs are a key component. The screening levels developed are based on the latest science and international approaches, and take account of Nigeriaspecific conditions, such as climate, land-use and patterns of human activity.

The principle behind a risk-based approach is to consider the mechanisms by which oil spill contamination can potentially impact biodiversity and human health. In the application of sustainable development principles, where the aim is for the benefit of undertaking remediation to be greater than the impact remediation activities can have on the environment, the goal is to avoid intrusive remediation techniques with serious impact to biodiversity (e.g. uprooting trees and vegetation to undertake remediation), unless absolutely necessary to protect human health. This work is currently in its final stages.

The initiative involved working with national Nigerian regulators, DPR and NOSDRA, and advocating for change to existing regulations, which currently require the company to remediate every oil spill area to the same level, rather than to base remediation on risks to human health and biodiversity.

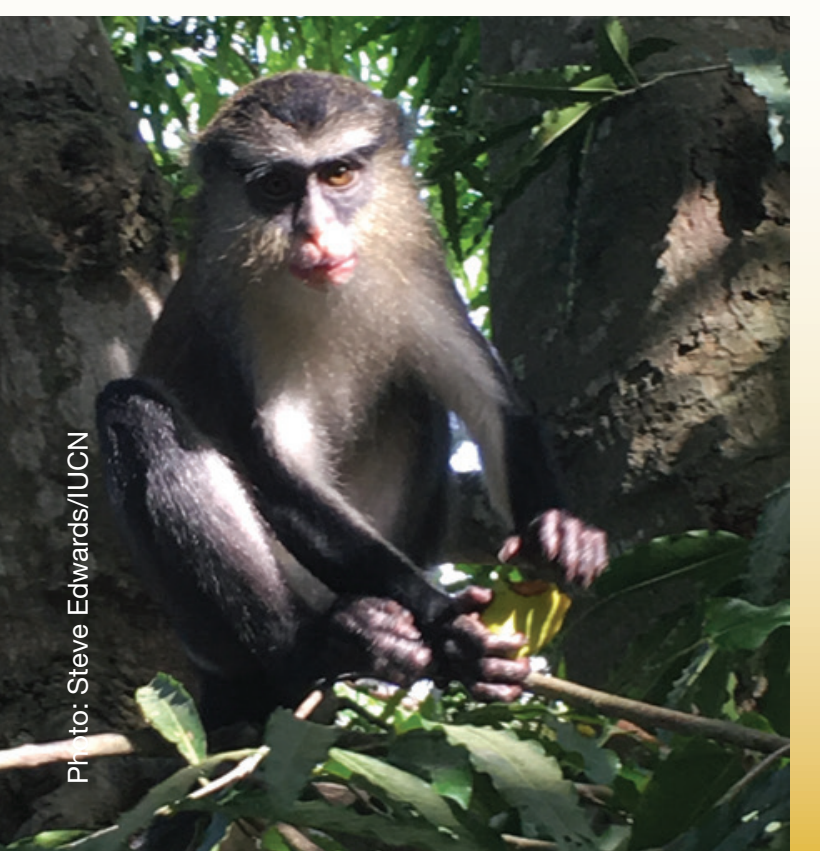

Final approval for use of the risk-based approach is expected in 2019, following the completion of pilot trials together with regulators at 10 sites across the Niger Delta. As part of the programme, the company has provided training for 150 DPR and NOSDRA personnel to support the implementation and assessment of remediation efforts. See Chapter 4 for more information on this work.

\section{- Strengthening biodiversity assessment}

As noted previously, the Panel's second major report and set of recommendations focused on helping SPDC develop a biodiversity conservation strategy and integrate these considerations into its operations. In the report, the IUCN NDP recognised SPDC as the industry leader in terms of considerations given to biodiversity in Nigeria's oil and gas industry operations, but it also encouraged further improvement. The Panel recommended that the impact assessment and biodiversity teams should be merged, as doing so would strengthen the biodiversity aspects of the impact assessment work conducted by SPDC. Practically speaking, this means that biodiversity experts would work together with the impact assessment team to conduct their fieldwork. If the impact assessment identifies potential for biodiversity impact, then biodiversity mitigation actions would be incorporated, with subsequent reporting. SPDC has now implemented these recommended changes.

Strengthening the biodiversity assessment capacity in the company required resources that the company needed to provide. The internal biodiversity expert, who took over coordination and follow-up of the implementation of the IUCN NDP's recommendations in June 2018, received external support to do so from the University of Uyo in Akwa lbom State in Nigeria, where SPDC funds a Biodiversity Chair (an independent initiative by SPDC). 


\section{- Emphasising prevention}

Many of the Panel's recommendations emphasised prevention and the need to reduce the number of oil spills overall. In response, SPDC teams have worked together internally to generate ideas for ways to accomplish this; for example, improving surveillance of facilities for early detection of third party activities.

Community engagement is crucial in this regard, as the surveillance is done by community contractors. SPDC is working to improve the competencies of community contractors and is developing tools for early reporting of any illegal practices detected in order to facilitate quick oil spill response. Internally there are significant resources allocated to prevention. There is a group looking at applying new technology, such as drones, to supplement the use of helicopters for daily surveillance, providing information to increase community competence, building an early warning system, and other initiatives.

\section{- Mainstreaming internal processes and capacity development}

The Panel's work throughout its tenure, and its support for strengthening company practice, has resulted internally in an overall upskilling of remediation execution teams, whose work is now assured on an ongoing basis through an updated management plan, and guidance documents. SPDC has also established a remediation assurance team (two soil and groundwater experts) that supports the implementation in two ways: training and competence development, and ongoing assurance, guaranteeing that the remediation work carried out by the execution teams follows internal standards. The team provides detailed assurance of the remediation activities throughout the process, from the Joint Investigation Reports produced together with regulators, through to final sign off and certification of sites. With a focus on improvement and implementation of best practice remediation, established processes now exist within the company to make continuous improvement of its remediation and rehabilitation work possible.

\section{- Influencing the broader corporate environment}

It is interesting to consider how the experience of SPDC as part of a large multi-national company might affect the other parts of the corporate environment. It is important to not overstate such attributions; however, certain elements of SPDC's experience with the IUCN NDP have provided insights which have been shared with other parts of the company. This is particularly relevant for other Shell companies operating in similar climatic conditions. The Mangrove Management Plan is one example. It can be helpful as a response to direct impact, or even when there has been no direct impact as a result of operational activity, it can support the company's wider social responsibility work for protection or rehabilitation of sensitive ecosystems.

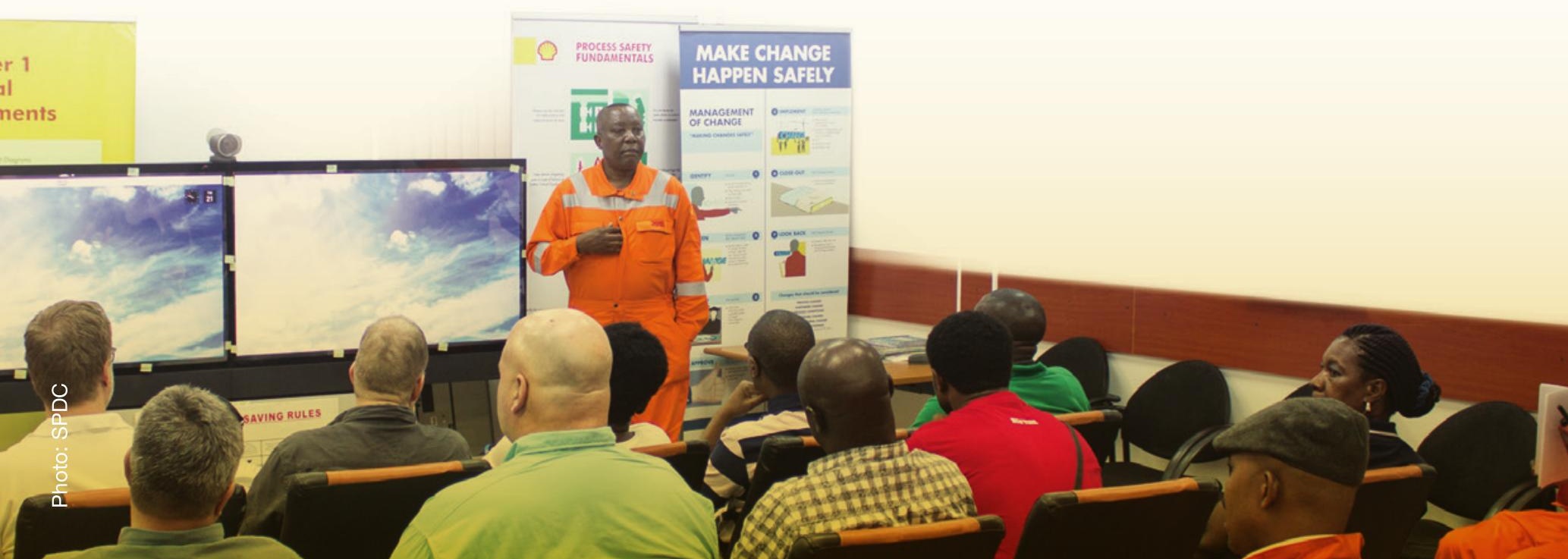




\section{Influence and impacts in IUCN}

\section{EXPERIENCING NEW THEMES AND CONTEXTS}

As the convener of the Panel, the IUCN NDP process provided IUCN with a number of new opportunities including moving into a thematic area beyond its traditional areas of expertise. This particular Panel's inquiry focused on bioremediation and chemistry, rather than on IUCN's familiar territory of species conservation and protected areas through community-based and rights-based approaches (RBAs).

Not only did the Panel provide IUCN with an opportunity to look deeply into a new area, but to work in a context that was unusually complex and controversial, due to the challenging political and social environment - an environment where Panel members and IUCN staff could not easily go in person to conduct their onsite work.

Saying "yes" to working with the Panel and SPDC in this new context helped strengthen capacity and confidence in IUCN to work in new fields and in highly complex environments, sparked the creation of new internal systems, and helped refine the ISTAP process, further improving the practice of future panels. More on each of these areas of influence below.

\section{- Working confidently on projects with a higher risk profile}

Because of its experience with the Panel, IUCN's risk tolerance and risk capacity have increased. Large complex projects such as this one are now less of an unknown for IUCN, and there are systems and processes in place, lessons learned, and value added from the outcomes of the experience. There is now more of a realisation of the risk profile the organisation is assuming when launching such a project, and more appetite to work on similar independent panel processes as a business strategy, even knowing that they are a higher risk. The experience with the Panel has further prepared IUCN, from an institutional perspective. The work with the Panel helped the organisation understand that it needed a more structured risk management and assessment process at the institutional level. In April 2018, the IUCN Council adopted an enterprise risk management policy, and future panels will have a risk assessment and management process in place, which will strengthen IUCN's risk capacity for similar work.

\section{- Bringing more expertise and learning opportunities into IUCN}

As the Panel process convened a set of scientific experts to work with IUCN and SPDC in a new area, it gave IUCN the opportunity to cast widely for the necessary expertise. The Panel process thus brought into IUCN's community additional technical competencies that could influence other areas of its work. A case in point: one of the Panel members was a mangrove expert and was instrumental in formulating the Panel's recommendations to SPDC on improving its mangrove forest rehabilitation work. This expert subsequently joined IUCN's Species Survival Commission (SSC), and became one of the founding members of a new IUCN-SSC Mangrove Specialist Group, now composed of over 100 members who support mangrove research and conservation projects globally. The new group is well positioned to provide inputs to other initiatives in this field.

In addition to new expertise, the geographic location of the Panel's work in Nigeria presented new challenges to IUCN, as there was no official IUCN office in the country. As Nigerian legal requirements stipulated that the Panel process required a Nigerian partner organisation, IUCN Member Nigerian Environmental Study Action Team (NEST) agreed to collaborate on the Niger Delta process. Through this partnership, IUCN gained valuable lessons on working closely with Members on extremely challenging issues. 
Overall, participating in the IUCN NDP process provided a valuable organisational learning opportunity for IUCN. It helped the IUCN community learn that it is possible to work in, and make an important contribution to, highly complex environments and that, as an organisation, it should not shy away from such opportunities and requests. They learned that while issues of oil spills appear intractable, there are methods and approaches to be explored.

Although this was a project outside the traditional area of work for the organisation, IUCN demonstrated that it can convene a technical panel by drawing upon its broader network to find the necessary expertise. Moreover, it showed that IUCN can catalyse change and have an impact at various levels, whether corporate, national, regional or potentially global - when other companies are able to benefit from the science-based outputs of such projects.

\section{- Helping inform the IUCN peer review system}

As oil spill remediation is a highly technical and specialised field, the IUCN NDP report provided an excellent opportunity to engage scientists and experts within IUCN's broader network on a controversial issue. The Panel's 2013 report provided an impetus to further develop and test a more formal peer review system within IUCN, including the creation of templates and an audit trail for gathering responses and providing comments.

Since then, IUCN's peer review system has been further refined and is now well established within the organisation, thus continuing to ensure quality knowledge products.

\section{- Establishing Independent Scientific and Technical Advisory Panels (ISTAPs)}

IUCN has developed a set of internal procedures for creating and managing ISTAPs, of which the IUCN Niger Delta Panel is a notable one. In 2014, IUCN published a report, Procedures for establishing and managing IUCN-supported Independent Scientific and Technical Advisory Panels, which states:

"IUCN must be able to demonstrate that the panels are independent, transparent, accountable and scientifically-rigorous, and that they engage openly with all relevant stakeholders. These procedures are mandatory and must be applied in full by any group of experts convened by IUCN..."

The IUCN Niger Delta Panel helped inform these procedures. As a result, the ISTAP approach proves that IUCN, its Members and partners can address controversial and challenging issues.

As the need to reconcile conservation and development becomes more common, the ISTAP approach has drawn the interest of financial institutions and companies. For example, following the experience from IUCN NDP, IUCN was requested by BHP Billiton following the Samarco tailings dam collapse in November 2015. Since then, IUCN established the independent Rio Doce Panel. 


\section{2.}

10

1)
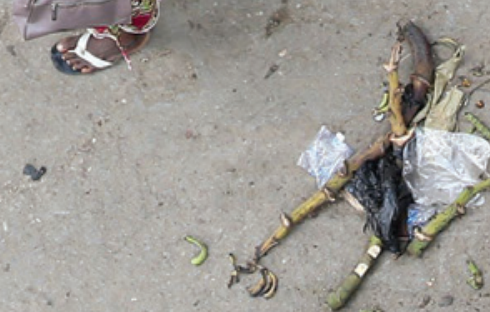
(4)

Qhe atras

(1)
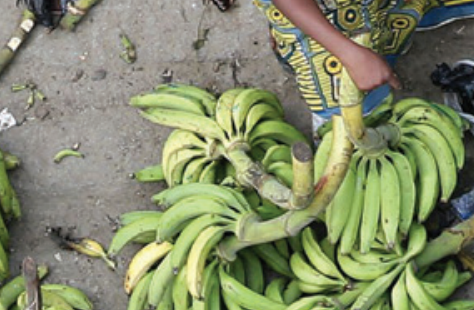
A
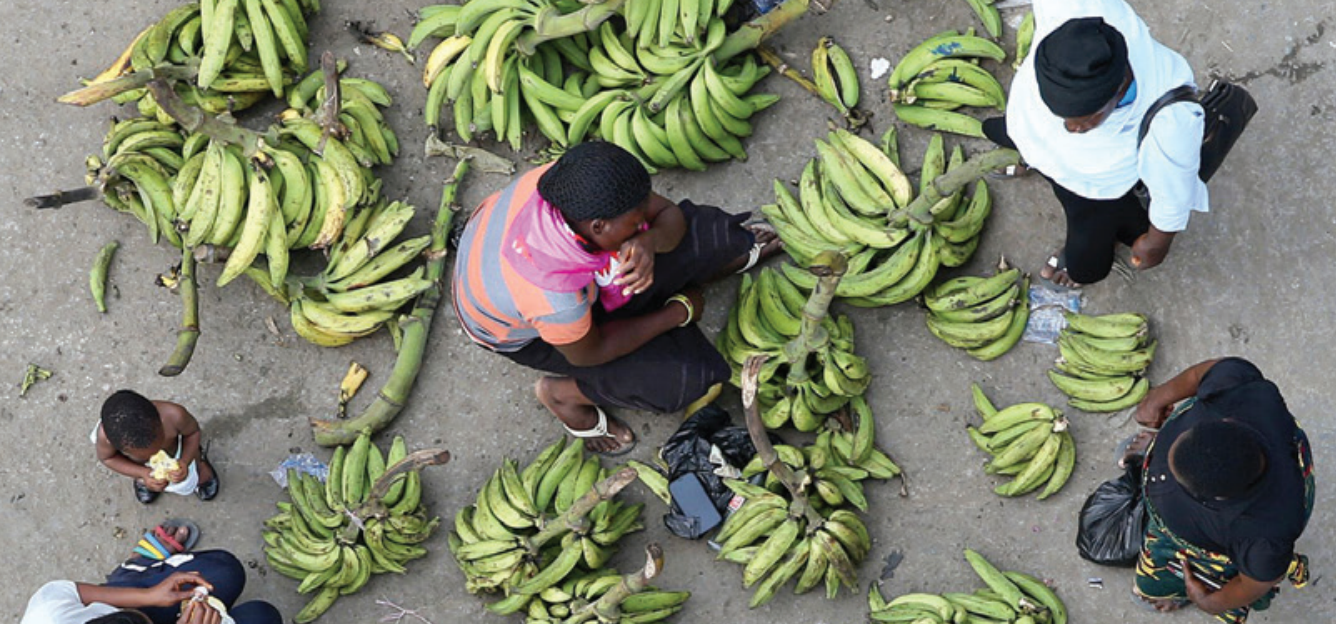

4034

क)
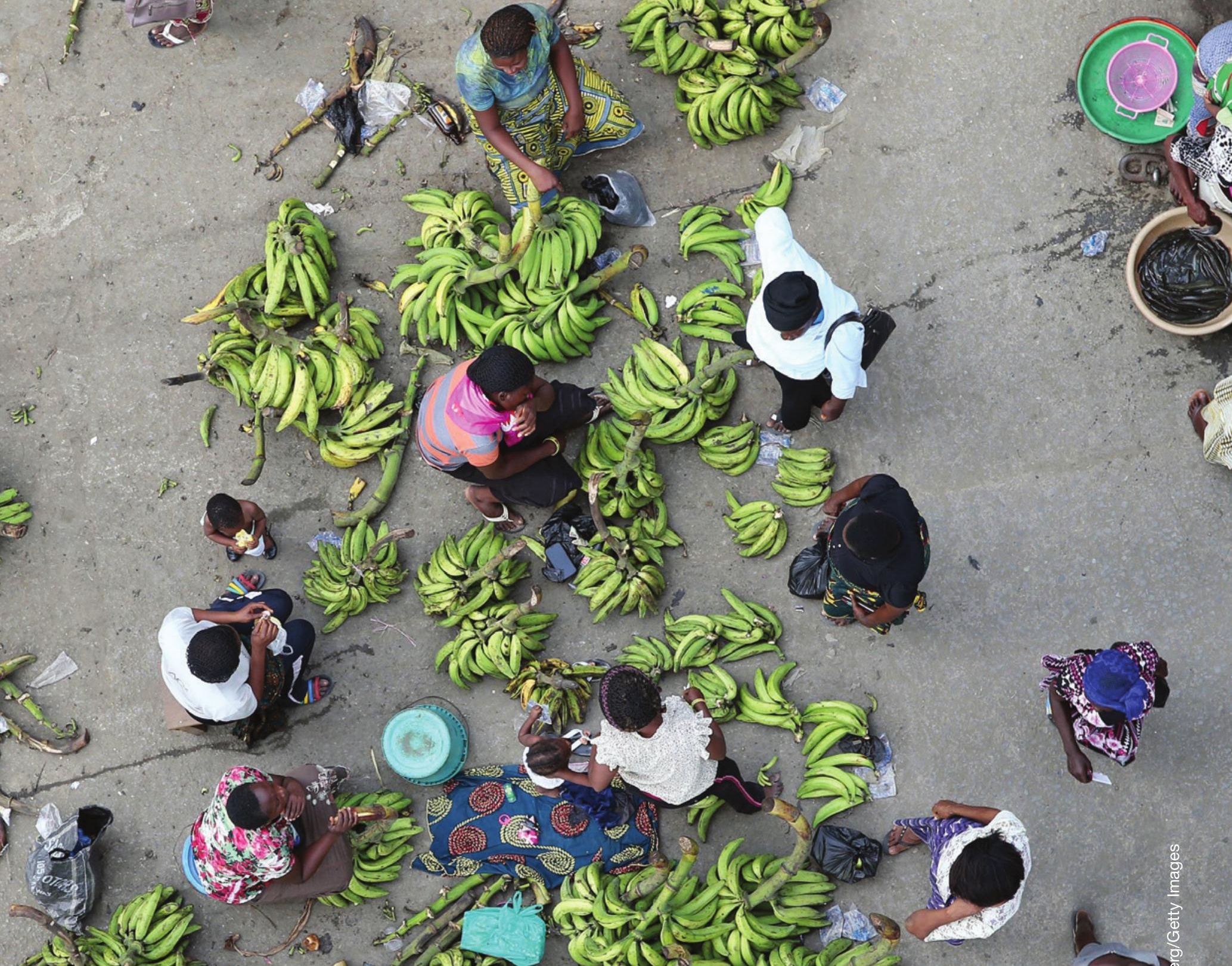

(40) 3500

cis

(it)

(iv)

(a)

1)

(102) (2010 cents

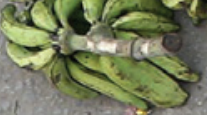

a) $(3,0$
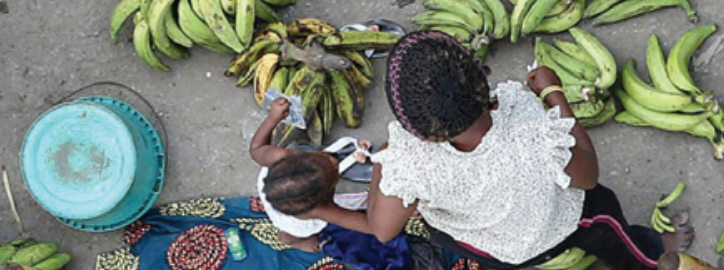

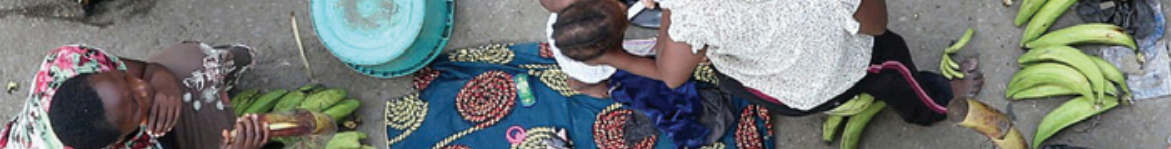

(n)

(a)

2.

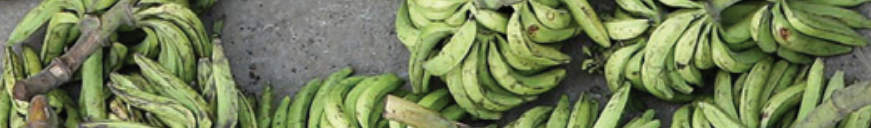
- 5 .
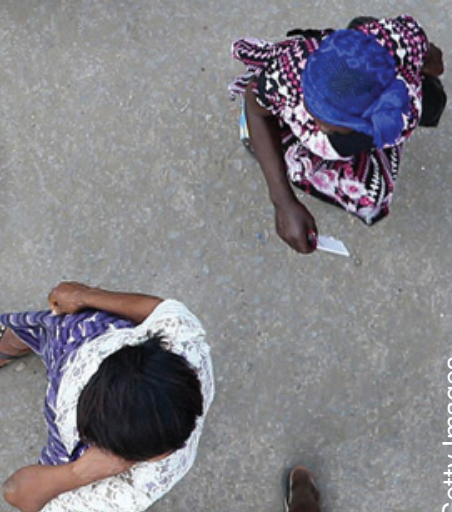


\section{Working with regulators}

To achieve more systemic change, regulations are an interesting leverage point. Through its work, the Panel advocated the use of a riskbased approach for SPDC's work. This in turn encouraged an SPDC initiative to collaborate with regulators in the development of a riskbased approach to remediation.

\section{SCALING UP NEW APPROACHES}

SPDC is now working with regulators from the DPR, the government department responsible for this regulation, to obtain permission to use a risk-based approach to oil spill remediation. It has also asked the DPR to consider including the use of a risk-based approach for managing land contamination in the updated Nigerian environmental regulations (Environmental Guidelines and Standards for the Petroleum Industry in Nigeria (EGASPIN)).

SPDC has held a number of capacity development workshops with regulators to share evidence and details, to increase regulators' understanding of the approach and its benefits, and to work with them to adapt the RBSLs approach to the climatic and social conditions found in Nigeria. Through this process, regulators have agreed to pilot the implementation of conceptual site models in the ecozones.

A working group of SPDC and regulators was established in October 2016 to review the data and agree how to proceed. Since its inception, this group has met five times and developed a set of recommended screening levels as presented in their report, "Tier 1 RiskBased Screening Levels (RBSLs) for soil and groundwater in the Niger Delta" (17 August 2017).
In February 2018, SPDC received the regulators' endorsement to pilot the approach at 10 selected sites within the Niger Delta. The working group requested SPDC to assist with the capacity building of regulators. Between February and May 2018, 150 staff from DPR and NOSDRA were trained, with international experts from Shell Group acting as facilitators. The curriculum and training materials for the course, "Application of risk-based screening levels (RBSLs) for soil and groundwater in the Niger Delta", were developed by soil and groundwater specialists in Shell and used data and the Niger Delta-specific CSMs, jointly developed with the IUCN NDP.

Through the pilot testing of the risk-based approach, regulators will participate in site assessments to establish correct exposure scenarios and target levels. Regulators will visit the sites periodically to assess the project remediation efforts and will certify the sites at completion. The pilots will run for four to five months per site, until mid-2019. 


\section{Influence in the community and on other initiatives}

\section{ENGAGING AT THE COMMUNITY LEVEL}

The Panel's work with SPDC to develop a new approach to remediation had consequences for the company's work with 10 local vendors who conduct oil response and remediation. There existed some opportunities to strengthen capacity of local vendors in their provision of services, particularly those that could support IUCN NDP recommendations, and so SPDC embarked on a process to build their capabilities.

Community contractors carry out a significant proportion of SPDC's remediation work, and by increasing the competencies of these locally-based vendors, they could better act as advocates for the company in the communities, where they and community members can see the long-term effect of oil spill pollution. This in turn raises awareness and helps communities ask better questions to understand cause and effect.

Overall, better data and information provided locally can encourage communities to resist and restrict efforts of people whose actions ultimately create some of the oil spills. As their comprehension increases, communities can say "no" to pipeline tapping, because they understand that the oil spills can have long-term effects on human health and the environment.

\section{ADDING TO THE BODY OF KNOWLEDGE AND LITERATURE}

The previously mentioned reports and articles produced as a direct or indirect result of the Panel's work have helped contribute to the body of knowledge available on this particular issue in a remote geographical area. Experts around the world who following the latest development in oil spill-related issues, mangrove degradation, the

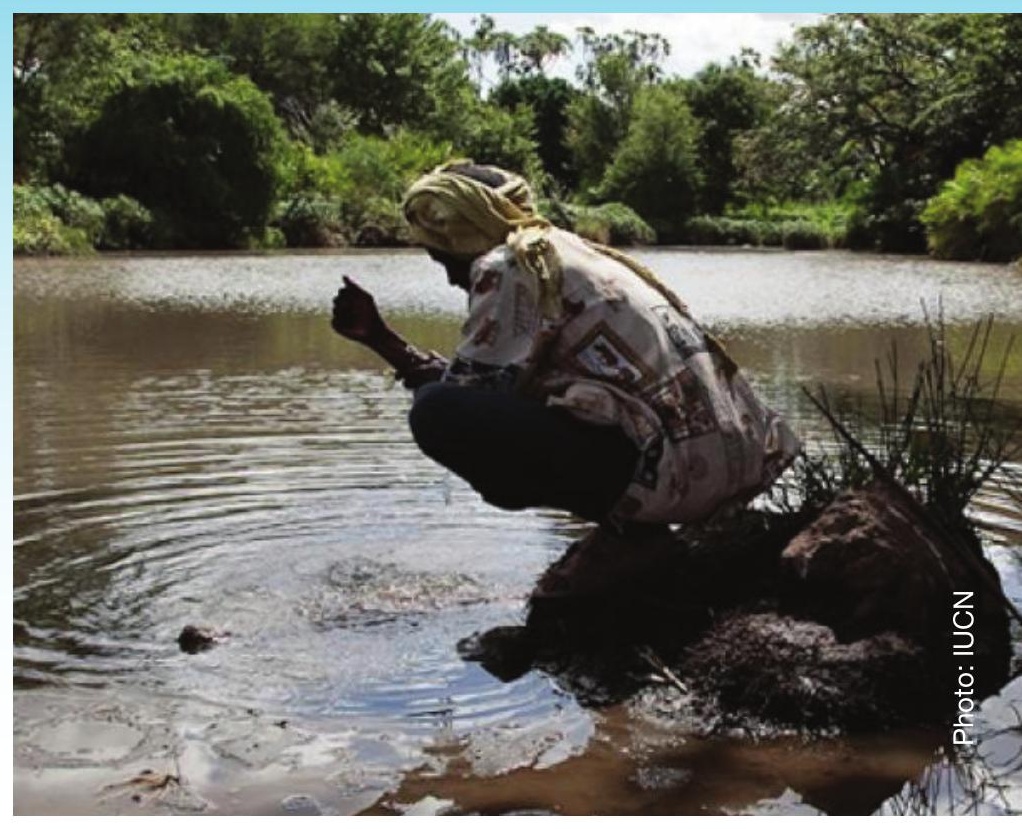

rehabilitation of oil contaminated land and soils, and the Niger Delta, now have another source of knowledge to draw upon for their work.

\section{BRINGING THE IUCN NDP RECOMMENDATIONS INTO OTHER FORUMS AND PROJECTS}

Although the IUCN NDP process has officially ended, the Panel members - all acknowledged experts in their fields - carry the recommendations forward in their professional work, integrating findings, where possible. What follows are just a few examples of this:

- One Panel member collaborated with the Intergovernmental Panel on Climate Change (IPCC) Special Report on the Ocean and Cryosphere in a Changing Climate and drew materials from the guidelines on mangroves. The same Panel member used the same guidelines and Panel recommendations for a Wetlands International project and for the International Blue Carbon Partnership, as part of his collaboration in a scientific working group with a special area on oil spills. 
- Another Panel member built upon interactions with communities and other stakeholders during the Panel's investigative work to help shape best practice for inclusive growth as part of his contribution to the Low Carbon Development Strategy for Nigeria. This input included how several aspects of livelihoods and biodiversity can be rehabilitated after remediation, and how to incorporate mitigation approaches in project delivery.

- The process and findings of the IUCN NDP have also been integrated into graduatelevel university teaching by another Panel member, who uses the NDP to address issues of extensive degradation of wetlands and mangroves.
The Panel members carry the learning and experience from their work on the NDP with them into their individual areas of work and influence. SPDC, Shell and IUCN colleagues also have substantive information and learning from the process to share, both in the form of the publications and their own experience. This has been shared in different forums - from scientific conferences to responsible investors' meetings - where the topic of Nigeria and the Niger Delta, oil spill remediation and biodiversity conservation are debated.

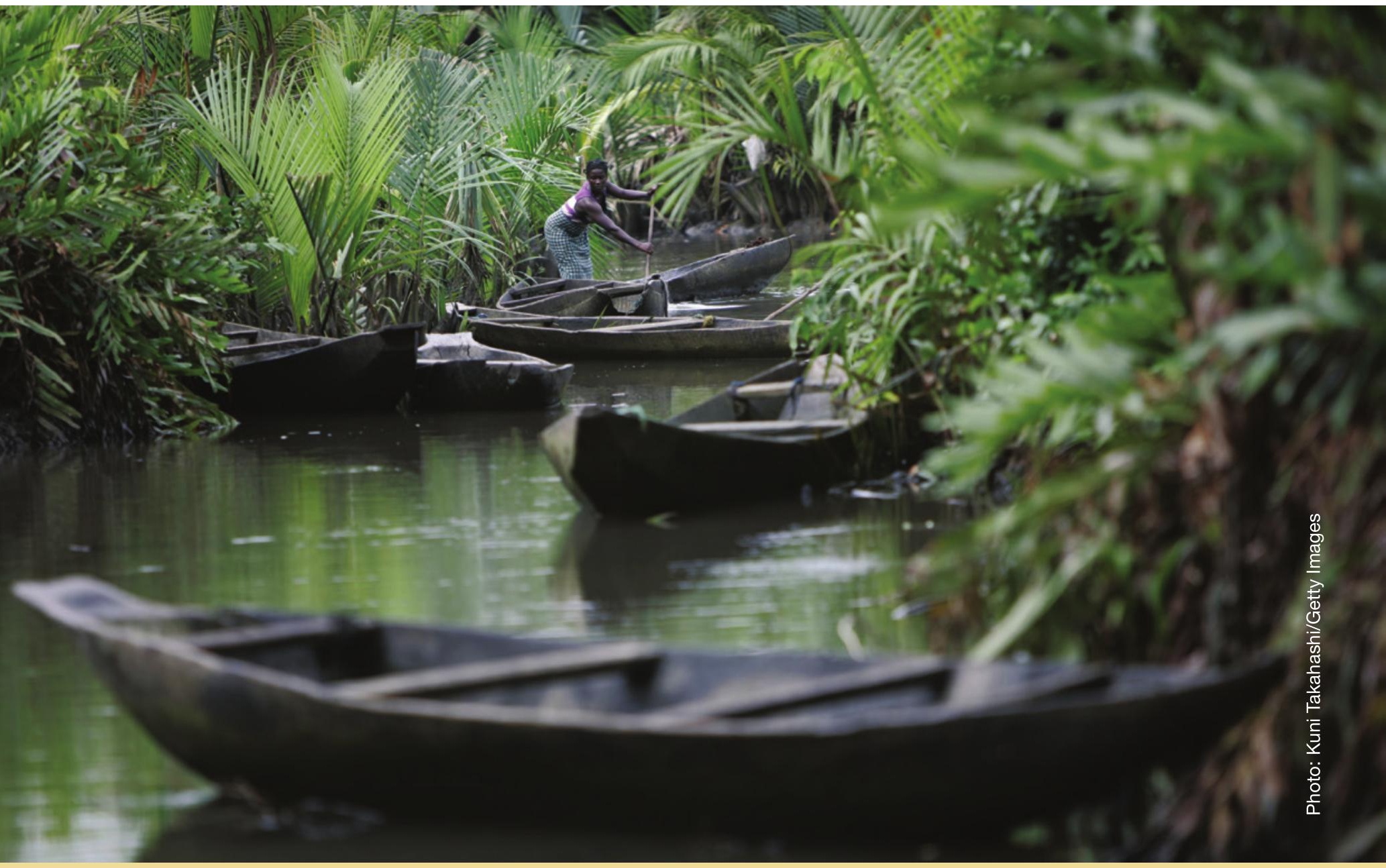




\section{Next steps and conclusion}

The Panel's formal work may have ended in 2016; even so their recommendations continue to inform the current work of SPDC. A Phase 2 process has been put into place and SPDC will provide a dedicated staff member as a part-time coordinator.

Phase 2 is supported by a technical working group - the Niger Delta Biodiversity Technical Advisory Group (BTAG). Composed of international and Nigerian experts, the Advisory Group has established a protocol framework to monitor the implementation of the recommendations and the sites that have been remediated from a biodiversity perspective. BTAG includes members from SPDC, Shell Group, IUCN, the Nigerian Conservation Foundation and Wetlands International, both IUCN Members, and several other independent experts. Its current timeframe is four to five years.

As the IUCN NDP experience shows, business and governments facing seemingly intractable, complex and controversial issues can benefit from external, independent and evidence-based recommendations. Involved parties have much to learn from engaging in such processes, which must be juxtaposed with the cost of businessas-usual. For this type of intervention to work effectively, it is essential to adhere to ISTAP principles and procedures to build trust and credibility among all the stakeholders.

Through its contribution in addressing the significant environmental challenges facing the Niger Delta and its people, the IUCN NDP has laid the groundwork for future research and partnerships. 


\section{Annex \\ List of interviews}

1. Dr Uzoamaka Egbuche, IUCN NDP Chair

2. Dr Muhtari Aminu-Kano, IUCN NDP Panel

3. Dr James Kairo, IUCN NDP Panel

4. Professor Dan Laffoley, IUCN NDP Panel

5. Professor Olaf Linden, IUCN NDP Panel

6. Kim Bye Bruun, SPDC

7. Pankyes Hirse, SPDC

8. Chinyere Ozumba, SPDC

9. Deric Quaile, (formerly) Shell Global Solutions

10. Rachel Asante-Owusu, IUCN

11. Gerard Bos, IUCN

12. Stephen Edwards, IUCN

13. Stewart Maginnis, IUCN 



\section{IUCN}

INTERNATIONAL UNION

FOR CONSERVATION OF NATURE

WORLD HEADQUARTERS

Rue Mauverney 28

1196 Gland

Switzerland

Tel +41229990000

Fax +41229990002

www.iucn.org

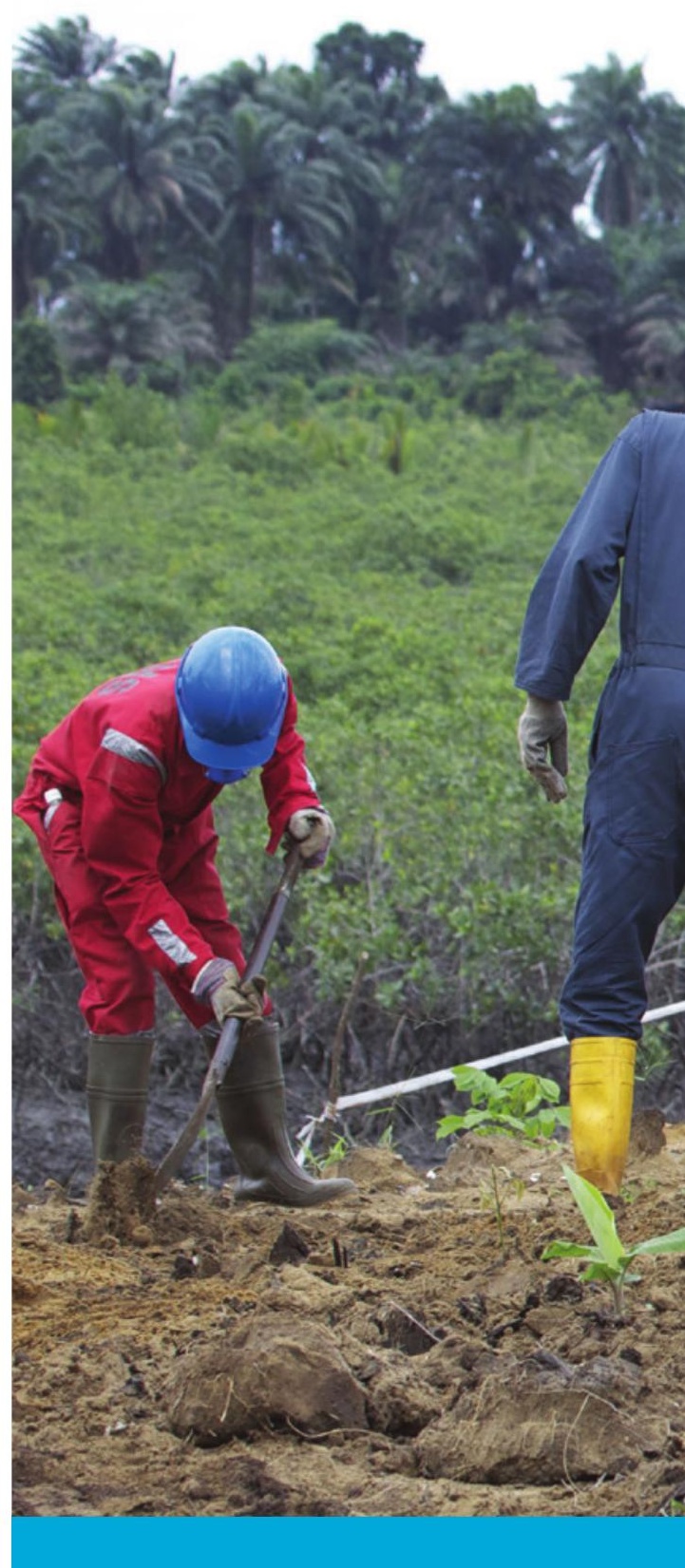

